\title{
PENINGKATAN KEMAMPUAN BACA TULIS AL-QUR'AN MAHASISWA PAI MELALUI PROGRAM MATRIKULASI BTQ
}

\author{
Listi Baihati 1) \\ Santika Lya Diah Pramesti 2)* \\ 1, 2 Program Studi Pendidikan Agama Islam, Fakultas Tarbiyah dan Ilmu Keguruan \\ Institut Agama Islam negeri (IAIN) Pekalongan \\ *E-mail: santikalyadiahpramesti@iainpekalongan.ac.id
}

\begin{abstract}
In this study, the author describes the problem of how to implement the BTQ matriculation program at IAIN Pekalongan. Is there an increase in Al-Qur'an literacy skills of PAI students through the BTQ matriculation program at IAIN Pekalongan. The purpose of this study was to determine the implementation of the BTQ matriculation program at IAIN Pekalongan and to find out whether there was an improvement in the Al-Qur'an literacy skills of PAI students through the BTQ matriculation program at IAIN Pekalongan. The approach used in this study is a quantitative approach using experimental methods. The results of the study can be concluded that the implementation of the BTQ matriculation program at Pekalongan IAIN is conducted once a week on Saturdays. To find out the ability of students to read and write the Qur'an, an examination or test is carried out both written tests and oral tests. The results of calculations through prerequisite tests and comparative tests show that the BTQ matriculation program can improve the Al-Qur'an literacy skills of PAI students. From the results of these calculations it can be concluded that there is a significant increase in the results of student test scores before partisipating in the BTQ matriculation program and after participating in the BTQ matriculation program.
\end{abstract}

Keywords: Improvement, Read Write Al-Qur'an, BTQ Matriculation Program

\begin{abstract}
Abstrak
Dalam penelitian ini, penulis memaparkan permasalahan tentang bagaimana pelaksanaan program matrikulasi BTQ di IAIN Pekalongan. Adakah peningkatan kemampuan baca tulis Al-Qur'an mahasiswa PAI melalui program matrikulasi BTQ di IAIN Pekalongan. Tujuan penelitian ini untuk mengetahui pelaksanaan program matrikulasi BTQ di IAIN Pekalongan dan untuk mengetahui adakah peningkatan kemampuan baca tulis Al-Qur'an mahasiswa PAI melalui program matrikulasi BTQ di IAIN Pekalongan. Pendekatan yang digunakan dalam penelitian ini adalah pendekatan kuantitatif dengan menggunakan metode eksperimen. Teknik analisis menggunakan uji prasyarat yang terdiri dari uji normalitas data dan uji homogenitas dan untuk pengujian hipotesis dengan uji komparasi uji t dua sampel berpasangan (sampel Paired test). Hasil penelitian dapat disimpulkan bahwa pelaksanaan program matrikulasi BTQ di IAIN Pekalongan dilakukan setiap satu minggu sekali pada hari Sabtu. Untuk mengetahui kemampuan mahasiswa dalam baca tulis Al-Qur'an, diadakan ujian atau tes baik tes tertulis maupun tes lisan. Hasil perhitungan melalui uji prasyarat dan uji komparasi menunjukan bahwa program matrikulasi BTQ dapat meningkatkan kemampuan baca tulis Al-Qur'an mahasiswa PAI. Dari hasil perhitungan tersebut dapat disimpulkan terdapat peningkatan yang signifikan pada hasil nilai tes mahasiswa sebelum mengikuti program matrikulasi BTQ dan sesudah mengikuti program matrikulasi BTQ.
\end{abstract}

Kata Kunci: Peningkatan, Baca Tulis Al-Qur'an, Program Matrikulasi BTQ 


\section{PENDAHULUAN}

IAIN Pekalongan merupakan perguruan tinggi agama Islam yang berada di tengah-tengah hiruk pikuk aktifitas warga Pekalongan yang terkenal sebagai kaum santri, mau tidak mau IAIN Pekalongan harus mampu menghasilkan lulusan-lulusan yang mempunyai distingsi khusus di bidang ilmu-ilmu keislaman, dari kompetensi yang paling dasar seperti baca tulis Al-Qur'an. Salah satu program studi di IAIN Pekalongan yaitu jurusan PAI yang merupakan salah satu program studi dari fakultas Tarbiyah dan Ilmu Keguruan yang mengemban misi dalam pengembangan kajian ilmuilmu agama Islam. Selain itu, juga mengemban misi program pendidikan profesional untuk menyiapkan calon guru PAI yang sesuai dengan bidang keahlian yang ditekuninya.

Mahasiswa sebagai calon guru PAI dituntut untuk menguasai BTQ demi menunjang keberhasilan kegiatan belajar mengajar, dimana pembelajaran pada jurusan PAI tidak terlepas dari baca dan tulis Al-Qur'an. Sebagaimana yang dikatakan Zakiah Daradjat mendefinisikan PAI merupakan suatu usaha sadar untuk membina dan mengasuh peserta didik agar senantiasa dapat memahami ajaran Islam secara menyeluruh (Kaffah). Lalu menghayati tujuan yang pada akhirnya dapat mengamalkan serta menjadikan Islam sebagai pandangan hidup (Heri Gunawan, 2013: 201).

Seorang guru atau dosen dituntut menguasai berbagai kompetensi (kecakapan) dalam melaksanakan profesi keguruanya agar dapat menciptakan lingkungan belajar yang baik bagi peserta didik, sehingga tujuan pengajaran dapat tercapai dengan optimal. Salah satu kompetensi yang harus dimiliki oleh seorang guru yaitu profesional. Dimana seorang guru harus memiliki kapasitas atau penguasaan yang mumpuni sesuai dengan bidang keahlian yang ditekuninya. Penyelenggaraan pendidikan dan pengajaran, mulai dari pendidikan dasar sampai dengan perguruan tinggi hanya akan efektif, jika dikelola oleh tenaga pendidikan atau guru yang profesioanal. Guru profesional yaitu guru yang memiliki kompetensi tertentu sesuai dengan persyaratan yang dituntut oleh profesi keguruan (Sudarwan Danim, 1994: 53).

Problema yang kemudian muncul salah satunya masalah dalam pembacaan AlQur'an. Telah kita ketahui kemampuan seorang muslim di era yang semakin modern ini sangat kurang memperhatikan pelafalan dalam membaca al-Qur'an baik dari segi makhrajnya ataupun tajwidnya. Hal ini dikarenakan kurang adanya kemauan untuk 
belajar serta bimbingan yang diberikan baik dari orang tuanya sendiri ataupun bimbingan dari guru.

Terkait dengan BTQ, setiap mahasiswa memiliki penguasaan yang berbeda-beda. Realisasi dalam meningkatkan kemampuan baca tulis Al-Qur'an pada mahasiswa, IAIN Pekalongan membuat program matrikulasi BTQ bagi semua mahasiswa pada masingmasing jurusan. Jumlah seluruh mahasiswa IAIN Pekalongan tahun akademik 2017/2018 yang mengikuti placement test BTQ berjumlah 2708 mahasiswa, termasuk di dalamnya 435 mahasiswa dari jurusan PAI tahun akademik 2017/2018 yang mengikuti test placement test BTQ. Hasil dari pengadaan placement test BTQ tersebut menghasilkan 239 mahasiswa yang dinyatakan lulus placement test BTQ dan 196 tidak lulus placement test BTQ atau remidi.

Program penunjang akademik berupa matrikulasi BTQ ini menjadi hal yang tidak boleh diabaikan. Pengadaan kelas matrikulasi BTQ ini bertujuan untuk meningkatkan pengetahuan dan kemampuan awal yang diperlukan mahasiswa dalam mengikuti kegiatan pembelajaran BTQ. Selain itu, memberikan pelayanan kepada mahasiswa untuk menjembatani kemampuan BTQ mahasiswa yang masih minim agar bisa menyetarakan dengan mahasiswa lainnya.

\section{METODE}

Pendekatan yang digunakan dalam penelitian ini adalah pendekatan kuantitatif jenis komparatif. Pendekatan kuantitatif adalah dengan mengumpulkan data yang berupa angka-angka (Nanang Martono, 2011: 20). Metode penelitian yang digunakan dalam penelitian ini menggunakan metode eksperimen. Penelitian dengan menggunakan metode ini dalam pemecahan masalahnya adalah dengan cara mengungkapkan hubungan sebab akibat antara dua variabel atau lebih melalui percobaan yang cermat (Syofian Siregar, 2014: 15).

Ada dua variabel yang dilakukan dalam penelitian ini yaitu hasil tes mahasiswa PAI tahun akademik 2017/2018 sebelum mengikuti program matrikulasi BTQ dan hasil tes mahasiswa PAI tahun akademik 2017/2018 setelah mengikuti program matrikulasi BTQ. Adapun yang menjadi anggota populasi dalam penelitian ini adalah seluruh mahasiswa PAI IAIN Pekalongan yang belum lulus placement test BTQ dan mengikuti program matrikulasi BTQ tahun akademik 2017/2018 dengan jumlah 196 mahasiswa. Sedangkan untuk pengambilan sempel dilakukan berdasarkan teori dari 
Suharismi Arikunto, apabila subjeknya kurang dari 100 lebih baik diambil semua sehingga penelitiannya merupakan penelitian populasi. Selanjutnya jika jumlah subjeknya besar dapat diambil antara $10-15 \%$ atau $20-25 \%$ atau lebih (Suharismi Arikunto, 1998: 120). Dalam penelitian ini jumlah sampel yang diambil 25\% dari jumlah anggota populasi 25\% x $196=49$. Sehingga diperoleh sampel dari penelitian ini yaitu 49 mahasiswa. Teknik Pengambilan Sampel dalam Penelitian ini peneliti menggunakan probability sampling dengan teknik rondom sampling yaitu pengambilan sampel dari populasi dilakukan secara acak tanpa memperhatikan strata yang ada dalam populasi (Sugiyono, 2008: 120).

Analisis data yang dilaksanakan dalam penelitian ini menggunakan uji analisis, meliputi: Uji Prasyarat yakni uji normalitas data, uji homogenitas, serta uji komparasi. Untuk menganalisis dua sampel berkolerasi dengan jenis data interval/rasio digunakan uji-t dua sampel berpasangan (sampel paired test). Berpasangan disini maksudnya adalah satu sampel mendapat perlakuan berbeda dari dimensi waktu.

\section{HASIL DAN PEMBAHASAN}

Program matrikulasi BTQ (M-BTQ) di IAIN Pekalongan merupakan kegiatan penunjang akademik yang diselenggarakan untuk memberikan pelayanan kepada mahasiswa dalam membantu meningkatkan kompetensi di bidang baca tulis Al-Qur'an (BTQ). M. Mufid, M. Pd. I salah satu pengelola program matrikulasi BTQ mengatakan: "Program matrikulasi BTQ ini ditujukan untuk mahasiswa yang dalam baca tulis AlQur'annya itu masih lemah". Program matrikulasi BTQ ini diharapkan dapat meningkatkan kemampuan BTQ mahasiswa.

Sebelum mahasiswa dinyatakan masuk kelas matrikulasi BTQ, semua mahasiswa baru diwajibkan mengikuti placement test BTQ. Sebagaimana yang dikatakan oleh Ma'mun, M. S.I selaku koordinator program matrikulasi BTQ, “Untuk tes sendiri hanya diadakan pas awal masuk kemudian yang tidak lulus masuk kelas matrikulasi BTQ, tes itu wajib diikuti oleh semua mahasiswa baru". Pengadaan plecements test BTQ dimaksudkan untuk melakukan penyaringan yang nantinya mahasiswa yang belum memenuhi standar terkait dengan pengetahuan dan pemahaman BTQ maka secara otomatis masuk kelas matrikulasi yang telah diadakan oleh IAIN Pekalongan.

Kegiatan M-BTQ dilaksanakan sebagaimana perkuliahan pada umumnya dengan beban waktu per- SKS yang dilaksanakan pada setiap hari Sabtu. Selain itu, dalam satu 
semester M-BTQ dilaksanakan sekurang-kurangnya selama 12 kali tatap muka selain UTS dan UAS. Sebagaimana yang dikatakan Ma'mun, M. S. I selaku koordinator program matrikulasi BTQ "Pembagian kelas dibagi berdasarkan prodi namun jika jumlahnya sedikit maka berbasis fakultas. Pembelajarannya diluar perkuliahan mahasiswa, mencari hari-hari efektif sama menyesuaikan hari dan jam kosong prodi."

Dalam kelas matrikulasi BTQ diadakan dua kali tes yaitu ujian tengah semester (UTS) dan ujian akhir semester (UAS) serta tes lisan. Pengadaan tes ini dilakukan untuk mengetahui peningkatan kemampuan mahasiswa dalam pemahamanya mengenai baca tulis Al-Qur'an. Jika dari hasil tes tersebut dinyatakan belum lulus, maka mahasiswa tersebut wajib mengulangi mengikuti kelas matrikulasi BTQ. Apabila dalam dua kali remidi (dua semester) masih belum lulus, maka diwajibkan untuk mengikuti ujian mandiri dengan salah satu koordinator BTQ secara tertulis dan lisan sampai ia benar-benar dinyatakan lulus. Selain itu, diperbolehkan bagi mahasiswa yang tidak lulus BTQ untuk memilih seseorang yang berkompeten dibidang BTQ (Ustadz/ Kiai) untuk memberikan bimbingan BTQ secara mandiri di luar kampus IAIN Pekalongan.

Sebagaimana yang dikatakan Nur Azizah S. Pd. I salah satu dosen pengampu MBTQ “ujian lisan saya target untuk bisa baca Qur'an dan saat pelaksanaan ujian lisan ini saya wajibkan mahasiswa membawa Qur'an sendiri, sedangkan untuk pelaksanaan ujian lisan diserahkan ke dosen masing-masing, kemudian ada ujian tertulis UTS dan UAS mba dan terakhir kehadiran. Tapi biasanya meskipun kehadiran rajin istilahnya hampir 50\% tapi bacanya masih kurang, saya lebih condong ke praktek ke bacanya. Meskipun nilainya bagus tapi praktiknya masih sangat kurang ya tidak saya luluskan. Jadi, kita harus benar-benar objektif lah Dalam memberikan nilai kelulusan". ${ }^{1}$ Begitu pula penuturan dari Pak Mufid "Pengadaan tes ini diuji oleh dosen pengajar, jika terdapat mahasiswa yang sampai 2 kali lebih tidak lulus BTQ maka akan diuji baik lisan maupun tertulis oleh pengelola BTQ". Standar penilaian yang dipakai dalam kegiatan matrikulasi baca tulis Al-Qur'an (M-BTQ) meliputi:

1) Kemampuan mahasiswa dalam membaca Al-Qur'an dan membaca tulisan (huruf Arab)

2) Kemampuan mahasiswa dalam menulis ayat-ayat Al-Qur'an dan menulis aksara Arab 
3) Kemampuan mahasiswa dalam mengetahui dan memahami ahkamul huruf (hukumhukum bacaan)

Berikut hasil nilai M-BTQ mahasiswa PAI sebelum mengikuti kelas matrikulasi BTQ dan sesudah mengikuti kelas matrikulasi BTQ tahun akademik 2017/2018 dari 49 mahasiswa, dengan syarat mahasiswa yang nilainya mencapai 70 maka dinyatakan lulus sedangkan mahasiswa yang nilainya kurang dari 70 maka dinyatakan remidi atau tidak lulus matrikulasi BTQ dan wajib mengulang matrikulasi BTQ berdasarkan ketentuan-ketentuan yang telah di buat pengelola matrikulasi BTQ tahun akademik

Berdasarkan tabel 1. uji normalitas untuk hasil nilai mahasiswa PAI sebelum mengikuti program matrikulasi BTQ dan sesudah mengikuti matrikulasi BTQ tahun Akademik 2017/2018 diperoleh nilai signifikansi ( $p$ )sebesar 0,113 $(p>0,05)$. Maka dapat disimpulkan bahwa untuk data hasil nila ites mahasiswa PAI sebelum mengikuti program matrikulasi BTQ dan sesudah mengikuti matrikulasi BTQ tahun Akademik 2017/2018 berdistribusi normal.

Tabel 1. One-Sample Kolmogorov-Smirnov Test

\begin{tabular}{llr}
\hline & & $\begin{array}{r}\text { Unstandardized } \\
\text { Residual }\end{array}$ \\
\hline $\mathrm{N}$ & Mean & \multicolumn{1}{c}{ 49 } \\
\cline { 2 - 3 } Normal Parameters ${ }^{\mathrm{a}, \mathrm{b}}$ & Std. Deviation & 14,946000000 \\
\cline { 2 - 3 } Most Extreme Differences & Absolute &, 171 \\
\cline { 2 - 3 } & Positive &, 146 \\
\cline { 2 - 3 } Kolmogorov-Smirnov Z & Negative &,- 171 \\
\hline Asymp. Sig. (2-tailed) & & 1,198 \\
\hline
\end{tabular}

a. Test distribution is Normal.

b. Calculated from data.

Uji homogenitas dilakukan untuk mengetahui apakah sampel yang diambil berasal dari populasi dengan varian homogen atau heterogen. Uji homogenitas pada penelitian ini menggunakan lavene test. Berikut hasil perhitungan uji homogenitas dengan lavene statistics, dimana perhitungan ini dilakukan dengan menggunakan SPSS. Kolom lavene statistics diperoleh nilai signifikansi sebesar 0.068. Hal tersebut menunjukan bahwa $p=0.068>0,05$, maka dapat dikatakan data berasal dari populasi yang homogen.

Setelah dilakukan uji normalitas dan uji homogenitas pada penelitian ini maka dilanjutkan untuk menggunakan teknik uji-t. Uji komparasi yang digunakan dalam 
penelitian ini yaitu menggunakan uji-t dua sampel berpasangan (sampel paired test). Berdasarkan hasil uji t diperoleh hasil $t_{0}=9,18$, maka $\left|t_{0}\right|=9,18$. Hasil uji memperoleh $\left|t_{0}\right|>t_{t}(9,18>2,011)$ pada taraf signifikan 5\%, maka $\mathrm{H}_{0}$ ditolak, $\mathrm{H}_{\mathrm{a}}$ diterima. Artinya terdapat perbedaan yang signifikan pada hasil nilai tes mahasiswa sebelum mengikuti program matrikulasi BTQ dan sesudah mengikuti program matrikulasi BTQ. Pada taraf 1\% diperoleh hasil $\left|t_{0}\right|>t_{t}(9,18>2,682)$, maka $H_{0}$ ditolak, $H_{a}$ diterima.

Artinya terdapat perbedaan yang signifikan pada hasil nilai tes mahasiswa sebelum mengikuti program matrikulasi BTQ dan sesudah mengikuti. Dari uji perbedaan tersebut dapat disimpulkan terdapat peningkatan yang signifikan pada hasil nilai tes mahasiswa PAI sebelum mengikuti program matrikulasi BTQ dan sesudah mengikuti program matrikulasi BTQ tahun Akademik 2017/2018.

Berdasarkan hasil analisis data, dapat diketahui bahwa terdapat perbedaan kemampuan mahasiswa sebelum mengikuti program matrikulasi BTQ dan sesudah mengikuti program matrikulasi BTQ. Dalam pelaksanaan matrikulasi BTQ ini populasi yang mencapai 196 mahasiswa PAI yang masuk dalam kelas matrikulasi BTQ hanya 49 mahasiswa yang aktif mengikuti kelas matrikulasi BTQ. Dimana 49 mahasiswa ini dijadikan peneliti sebagai sampel.

Ketidakaktifan yang terjadi pada mahasiswa dikarenakan semangat mereka untuk belajar BTQ semakin melemah atau menurun, tak jarang permasalahan ini terjadi pada semester genap. Bagi mahasiswa yang nilainya kurang dari 70 maka harus mengulang di semester selanjutnya. Berdasarkan penelitian, mahaisiswa yang remidi atau tidak lulus M-BTQ sampai dua kali semester maka di semester selanjutnya harus melakukan ujian mandiri pada pengelola BTQ sampai ia benar-benar dinyatakan lulus.

Dari hasil penelitian sebagaimana telah dikemukakan pada bagian sebelumnya, memberikan gambaran bahwa program matrikulasi BTQ dapat memberikan sumbangan yang lebih baik terhadap kemampuan mahasiswa, sehingga dapat dijadikan sebagai wahana untuk mengembangkan kemampuan baca tulis Al-Qur'an. Pada akhirnya diharapkan mahasiswa dapat membaca Al-Qur'an dengan baik serta dapat menerapkannya dalam kehidupannya sehari-hari. Pada dasarnya program matrikulasi BTQ di tahun akademik 2017/2018 memiliki perkembangan yang semakin maju dibanding tahun-tahun sebelumnya. Hal ini terlihat dari segi adminstrasinya, dimana program matrikulasi BTQ saat ini dibawah pimpinan langsung dari Warek 1 dan berpusat langsung pada kordinator pengelola BTQ. 
IAIN Pekalongan juga semakin memperhatikan baik pada dosen pengajar BTQ ataupun mahasiswa yang mengikuti matrikulasi BTQ dengan diberikan arahan dan difasilitasi dengan beberapa kebijakan yang berpedoman pada buku pelaksanaan matrikulasi baca tulis Al-Qur'an. Selain itu, hal lain yang menjadi hambatan pelaksanaan matrikulasi BTQ yaitu kurangnya kesadaran mahasiswa dalam mengikuti kelas matrikulasi BTQ. Sehingga, diperlukan pengajaran dan arahan yang maksimal khususnya pada mahasiswa yang kurang aktif dalam mengikuti kelas matrikulasi BTQ.

\section{KESIMPULAN DAN SARAN}

\section{Kesimpulan}

Pelaksanaan program matrikulasi BTQ di IAIN Pekalongan dilakukan setiap satu minggu sekali pada hari Sabtu selama 12 kali tatap muka. Pelaksanaan program matrikulasi BTQ dilaksanakan sesuai dengan buku pedoman pelaksanaan matrikulasi BTQ dengan memberikan pengajaran makharijul khuruf, tajwid dan ghorib. Selain itu, program matrikulasi merupakan salah satu upaya yang dijadikan untuk meningkatkan kemampuan mahasiswa dalam baca tulis Al-Qur'an. Untuk mengukur tingkat kemampuan mahasiswa IAIN pekalongan mengenai kemampuan BTQ-nya, maka dalam kelas matrikulasi BTQ diadakan ujian atau tes baik tes tertulis maupun tes lisan. Selain dari bentuk tes, standar kelulusan matrikulasi BTQ juga diambil dari ujian praktik mengenai kelancaran dan pemahamanya dalam baca tulis Al-Qur'an dan hal ini menjadi tolok ukur utama kelulusan matrikulasi BTQ.

Program matrikulasi BTQ dapat meningkatkan kemampuan baca tulis Al-Qur'an mahasiswa PAI tahun Akademik 2017/2018 sebelum mengikuti program matrikulasi BTQ dan sesudah mengikuti program matrikulasi BTQ. Hasil peningkatan ini terbukti dari hasil uji komparasi $\left|t_{0}\right|>t_{t}(9,18>2,011)$ pada taraf signifikan 5\%, maka $\mathrm{H}_{0}$ ditolak, $\mathrm{H}_{\mathrm{a}}$ diterima dan pada taraf $1 \%$ diperoleh hasil $\left|\mathrm{t}_{0}\right|>\mathrm{t}_{\mathrm{t}}(9,18>2,682)$, maka $\mathrm{H}_{0}$ ditolak, $\mathrm{H}_{\mathrm{a}}$ diterima. Dari hasil perhitungan tersebut dapat disimpulkan yaitu terdapat peningkatan yang signifikan pada hasil nilai tes mahasiswa sebelum mengikuti program matrikulasi BTQ dan sesudah mengikuti program matrikulasi BTQ.

\section{Saran}

Hendaknya program BTQ ini senantiasa dilaksanakan dan selalu mendapat monitoring dan evaluasi dari bidang akademik sehingga akan lebih bermanfaat, berguna dan berdaya saing. 


\section{DAFTAR PUSTAKA}

AF, Hasanuddin. 1995. Perbedaan Qira'at dan Pengaruhnya Terhadap Istinbath Hukum Dalam Al-Qur'an. Jakarta: PT Raja GrafindoPersada.

Ali, M. 2014. Strategi Manajemen Mutu Pelajaran Bahasa Arab Melalui Program Matrikulasi Di Madrasah Aliyah Darut Taqwa Sengonagung Pasuruan. Pasuruan: Jurnal Review Pendidikan Islam. Vol. 1. No. 1.

Al-Munawar, Said Agil Husin. 2005. Al-Qur'an Membangun Tradisi Kesalehan Hakiki. Ciputat: PT Ciputat Press.

Aminuddin. 2012. Implementasi Metode Tutorial Sebaya Dalam Meningkatkan Prestasi Baca Tulis Al-Qur'an Peserta Didik Kelas VIII Di SMP 1 Wiradesa Kabupaten Pekalongan. Pekalongan: Jurnal Pendidikan al-Qalam. Vol. VI.

Arikunto, Suharismi. 1998. Prosedur Penelitian: Suatu Pendekatan Praktek. Jakarta: PT Rineka Cipta.

Asmani, Jamal Ma’mur. 2011. Penelitian Pendidikan. Jogjakarta: DIVA Press.

Astuti, Rini. 2015. Peningkatan Kemampuan Membaca Al-Qur'an Pada Anak Attention Deficit Disorder Melalui Metode Al-Barqy Berbasis Applied Behavior Analysis. Jakarta: Jurnal Pendidikan Anak Usia Dini. Vol. 7.

Danim, Sudarwan Danim. 1994. Media Komunikasi Pendidikan: Pelayanan Profesional Pembelajaran dan Mutu Hasil Belajar. Jakarta: Bumi Aksara.

Faisol. 2010. Cara Mudah Belajar Ilmu Tajwid. Malang: UIN Maliki Press.

Gunawan, Heri. 2013. Kurikulum dan Pembelajaran Pendidikan Agama Islam. Bandung: Alfabeta.

Hadi, Sutrisno. 2015. Metode Riset. Yogyakarta: Pustaka Pelajar.

Hamid, Abdul. 2010. Mengukur Kemampuan Bahasa Arab untuk Studi Islam. Malang: UIN Maliki Press.

Hidayat, Komaruddin. 1996. Memahami Bahasa Agama: Sebuah Kajian Hermeutik. Jakarta: Paramadina.

Khon, Abdul Majid. 2011. Praktikum Qira'at: Keanehan Bacaan Al-Qur'an Qira'at 'Ashim Dari Hafish. Jakarta: AMZAH.

Maqbulah, Umu Aisyiatul. 2015. Pengaruh kegiatan ekstrakurikuler BTQ terhadap kemampuan siswa dalam membaca al-Qur'an di SMK Muhammadiyah Kesesi Kabupaten Pekalongan. Pekalongan: Perpustakaan IAIN Pekalongan. 
Martono, Nanang. 2011. Metode Penelitian Kuantitatif: Analisis Isi dan Analisis Data Sekunder. Jakarta: Rajawali.

Mudhofir, Ali. 2013. Pendidik Profesional, Konsep, Strategi, Dan Aplikasinya Dalam Peningkatan Mutu Pendidik Di Indonesia. Jakarta: Rajawali Pers.

Muhadjir, Noeng. 1998. Metode Penelitian Kualitatif . Yogyakarta: Rike Sarasin.

Muhaimin.2004. Paradigma Pendidikan Islam: Upaya Mengefektifkan Pendidikan Agama Islam di Sekolah. Bandung: PT Remaja Rosdakarya.

Mulyana, Rohmat. 2011. Mengartikulasikan Pendidikan Nilai. Bandung: Alfabeta.

Mulyono, Abdurahman. 1999. Pendidikan Bagi Anak Berkesulitan Belajar. Jakarta: PT Rineka Cipta.

Mustaqim \& Abdul Wakhid. 2003. Psikologi Pendidikan. Jakarta: PT Rineka Cipta.

Muzani, Moh. 2015. Peningkatan Kemampuan Membaca Al-Qur'an Melalui Metode Tartil Pada Siswa Kelas IV Madrasah Ibtidaiyah Walisongo Bugangan Kedungwuni Pekalongan. Pekalongan: Perpustakaan IAIN Pekalongan, 2015).

Purwanto, Erwan Agus \& Dyah Ratih Sulistyastuti. 2011. Metode Penelitian Kuantitatif Untuk Administrasi Publik dan Masalah-masalah Sosial. Yogyakarta: Gaya Media.

Purwanto. 2011. Statistik Untuk Penelitian. Yogyakarta: Pustaka Belajar.

Salafudin \&Nalim. 2014. Statistik Inferensial. Pekalongan: STAIN Pekalongan Press.

Shalihah, Khadijatus. 1983. Perkembangan Seni Baca al-Qur'an dan Qiraat Tujuh di Indonesia. Jakarta: Pustaka Alhusna.

Siregar, Syofiyan. 2014. Statistik Parametik Untuk Penelitian Kuantitatif. Jakarta: Bumi Aksara.

Subagyo, Joko. 1998. Metode Penelitian Suatu Pendekatan. Jakarta: PT Rineka Cipta.

Sugiyono. 2008. Metode Penelitian Pendidikan: Pendekatan kuantitatif, Kualitatif, dan $R \& D$. Bandung: Alfabeta.

Surasman, Otong. 2002. Metode Insani: Kunci Praktis Membaca Al-Qur'an Baik dan Benar. Jakarta: Gema Insani Press.

Susiyanty, Utin Desy. 2016. Eksperimentasi Matrikulasi Ditinjau Dari Kecerdasan Interpersonal Mahasiswa Semester Program Studi Pendidikan Matematika IKIP PGRI Pontianak. Pontianak: Jurnal Pendidikan Informatika dan Sains, Vol. 5. N0. 1. 